Chronic Obstructive Pulmonary Diseases:

Journal of the COPD Foundation

\author{
Original Research
}

\title{
The Role of Inhalation Delivery Devices in COPD: Perspectives of Patients and Health Care Providers
}

Nicola A. Hanania, MD, MS ${ }^{1}$ Sidney Braman, $\mathrm{MD}^{2}$ Sandra G. Adams, MD, $\mathrm{MS}^{3,4}$ Ruth Adewuya, $\mathrm{MD}^{5}$ Arzu Ari, PhD ${ }^{6}$ JoAnn Brooks, $\mathrm{PhD}^{7}$ Donald A. Mahler, $\mathrm{MD}^{8}$ Jill A. Ohar, MD 9 Jay Peters, $\mathrm{MD}^{3}$ Shahin Sanjar, $\mathrm{PhD}^{10}$

\section{Abstract}

Background: Inhaled medications form the foundation of pharmacologic treatment for chronic obstructive pulmonary disease (COPD). The Delivery Makes a Difference (DMaD) project was conducted to better understand health care provider (HCP) and patient perspectives about the role of inhalation delivery devices in COPD, and to examine the nature of educational efforts between HCPs and patients on proper device technique.

Methods: Data were derived from 2 original quantitative, web-based, descriptive, cross-sectional surveys distributed to HCPs who manage COPD $(n=513)$ and patients with COPD $(n=499)$ in the United States. Descriptive statistics were used to assess data across important demographic variables. Inferential statistics were used to assess differences in attitudinal, descriptive, and behavioral measures that were cross-tabulated with demographic data.

Results: When prescribing medication for newly diagnosed patients with stable or unstable COPD, only $37 \%$ of HCPs considered type of device to be highly important, with only $45 \%$ of HCPs assessing device technique in every newly diagnosed patient. Patients with COPD were also relatively unconcerned with proper device technique (64\% never concerned), regardless of their COPD severity. Although patients did not identify education as a significant impediment to proper device use, they reported inconsistent educational experiences.

Conclusions: We found that HCPs and patients prioritize medication over device when selecting treatments, showing limited concerns about proper device use. These results highlight the need to coordinate professional education with patient-directed educational efforts to further promote proper device selection and use in COPD management.

\begin{abstract}
Abbreviations: chronic obstructive pulmonary disease, COPD; Delivery Makes a Difference, DMaD; health care provider, HCP; metereddose inhaler, MDI; dry-powder inhaler, DPI; soft mist inhaler, SMI; small volume nebulizer, SVN; pulmonologist, PUD; primary care physician, PCP; non-physician provider, NPP; Medication Adherence Report Scale, MARS-5; modified Medical Research Council Dyspnea Scale, mMRC

Funding Support: Sunovion Pharmaceuticals Inc., provided funding for the implementation of the survey and medical writing but did not influence the design, conduct of the study, or content of the submitted manuscript.

Date of Acceptance: December 14, 2017

Citation: Hanania NA, Braman S, Adams SG, et al. The role of inhalation delivery devices in COPD: Perspectives of patients and health care providers. Chronic Obstr Pulm Dis. 2018;5(2):111-123. doi: https://doi.org/10.15326/jcopdf.5.2.2017.0168
\end{abstract}

\section{This article contains an online supplement.}

1 Section of Pulmonary and Critical Care Medicine, Baylor College of Medicine, Houston, Texas

2 Icahn School of Medicine at Mount Sinai, New York, New York

3 University of Texas Health Science Center, San Antonio

4 South Texas Veterans Health Care System, San Antonio

5 American College of Chest Physicians, Glenview, Illinois
6 Texas State University, San Marcos

7 Indiana University Health, Bloomington

8 Geisel School of Medicine at Dartmouth, Hanover, New Hampshire

9 Wake Forest Health University Medical Center, Winston-Salem, North Carolina

10 Sunovion Pharmaceuticals Inc., Marlborough, Massachusetts 


\section{Address correspondence to:}

Nicola A. Hanania, MD, MS

Baylor College of Medicine

1504 Taub Loop

Houston, TX 77030

Email: hanania@bcm.edu

Phone: 713-873-3454

\section{Keywords:}

COPD; inhalation device; inhalation therapy

\section{Note: Part of this material was presented as an abstract at the American Thoracic Society International Conference in May 2017.}

\section{Introduction}

Inhaled medications form the foundation of pharmacologic treatment for chronic obstructive pulmonary disease (COPD). ${ }^{1}$ Inhaled delivery enables targeting medication to the airways, enabling a rapid effect with a relatively low dose of medication, thus lowering the potential for systemic bioavailability. ${ }^{2}$ Several inhalation device types are available, including metered-dose inhalers (MDIs), dry-powder inhalers (DPIs), soft mist inhalers (SMIs), and small volume nebulizers (SVNs). Each of these devices has unique attributes to consider when selecting treatment for a specific patient (Table 1)..$^{2-5}$ Patient-specific factors, such as COPD severity, comorbidities, and cognitive function may affect the patient's ability to use a particular device, ${ }^{5}$ as may patient perceptions of medication efficacy and device convenience, ease of use, and cost. ${ }^{4,6}$ Insurance providers and pharmacy formularies are also factors in device selection decisions. ${ }^{6}$

After device selection, initial training and follow-up assessment of technique are imperative, ${ }^{7}$ as poor inhaler technique has been cited as a major reason for the ineffective management of $\mathrm{COPD}^{2,5,8}$ A 2011 study by Melani et al demonstrated that the incidence of critical mistakes in device use among patients with COPD and/or asthma ranged from $12 \%$ to $44 \%$ depending on device, and that misuse was associated with an increased risk of hospitalization, emergency department visits, and poor disease control. ${ }^{8}$ Similarly, data from Loh and colleagues showed that suboptimal peak inspiratory flow, which is associated with the misuse of DPIs, increased the risk for 90-day COPD-related and all-cause hospital readmissions. ${ }^{9}$ Critical errors when using MDIs or DPIs are especially frequent in the primary care setting and among elderly patients (i.e.,

\section{Table 1. Device-Specific Considerations for Inhalation Delivery Systems ${ }^{2-5}$}

\begin{tabular}{|c|c|}
\hline & Device-Specific Considerations \\
\hline \multirow{3}{*}{$\begin{array}{l}\text { Metered-dose } \\
\text { Inhaler }^{3}\end{array}$} & Most commonly prescribed device \\
\hline & Requires hand-breath coordination \\
\hline & Multi-dose \\
\hline \multirow{3}{*}{$\begin{array}{l}\text { Dry Powder } \\
\text { Inhaler }^{3}\end{array}$} & Breath actuated; requires adequate \\
\hline & inspiratory flow (varies by device) \\
\hline & Single or multi-dose \\
\hline \multirow{2}{*}{$\begin{array}{l}\text { Soft Mist } \\
\text { Inhaler }\end{array}$} & Aerosol or fine mist, without a propellant \\
\hline & $\begin{array}{l}\text { Less hand-breath coordination than } \\
\text { metered-dose inhalers }\end{array}$ \\
\hline \multirow[t]{3}{*}{$\begin{array}{l}\text { Small Volume } \\
\text { Nebulizer }^{2}\end{array}$} & $\begin{array}{l}\text { Passively deliver inhaled medication to } \\
\text { the lungs in a fine mist }\end{array}$ \\
\hline & $\begin{array}{l}\text { Does not require hand-breath coordination } \\
\text { or any specific technique }\end{array}$ \\
\hline & $\begin{array}{l}\text { Less portable, needs a power source, longer } \\
\text { treatment times, and requires daily cleaning }\end{array}$ \\
\hline
\end{tabular}

$\geq 65$ years). ${ }^{10}$ Sulaiman and colleagues demonstrated that mean inhaler adherence, assessed as time of use, interval between doses and proper technique, was only $22.6 \%$ in a group of 244 patients (mean age, 71 years) with COPD recently discharged from the hospital. ${ }^{11}$ Inhaler technique improvement and training have been shown to benefit COPD outcomes. ${ }^{12}$ Indeed, the 2017 Global Initiative for Chronic Obstructive Lung Disease emphasizes the importance of regular inhaler technique assessment by health care providers (HCPs). ${ }^{1}$ Despite these recommendations, many HCPs lack the awareness, knowledge, and training needed to instruct their patients on proper inhaler use. ${ }^{13,14}$

We conducted the Delivery Makes a Difference, or $\mathrm{DMaD}$, study to better understand $\mathrm{HCP}$ and patient perspectives about the role of inhalation delivery devices in COPD. We sought to quantify HCP and patient knowledge, attitudes, beliefs, and behaviors about inhalation devices, and to examine the nature of educational efforts between HCPs and patients on proper device technique.

\section{Materials and Methods}

\section{Study Design}

The study included 2 quantitative, web-based, descriptive, cross-sectional surveys: 1 targeting $\mathrm{HCPs}$ and another targeting patients with COPD in the United States. A random sample of HCPs 
was chosen from a proprietary American College of Chest Physicians database of pulmonologists (PUDs), respiratory care practitioners, physician assistants, and nurse practitioners. A nonprobability sample of primary care physicians (PCPs) and physician assistants was obtained using a syndicated opt-in research panel of HCPs. Patients were randomly chosen from a panel of individuals with self-identified COPD.

Health care providers who did not self-identify as a PUD, family practitioner, general internal medicine practitioner, nurse practitioner, physician assistant, or respiratory care practitioner on an initial survey screening question were excluded from participating in the survey. Physician assistants and nurse practitioners were excluded if they did not indicate practicing in a primary care or pulmonology setting. Patients were excluded if they did not indicate a diagnosis of chronic bronchitis, emphysema, or COPD upon screening. To account for survey respondents who may have filled out the survey without reading the questions, time for survey completion was monitored for each participant, and surveys with completion times that were considerably shorter than the mean were excluded from the analysis. Details of the design, content, and response rate calculations for both surveys are in the online data supplement.

\section{Sample Size and Data Analyses}

A total of 513 survey responses were collected from HCPs (40.8\% were PUDs, 29.2\% PCPs), and 30\% non-physician providers (NPPs) (physician assistants, respiratory care practitioners, and nurse practitioners). A total of 505 survey responses were collected from patients. Our sample size provided a margin of error of $\pm 4.4 \%$ for both surveys. Descriptive statistics were used to assess data distributions across important demographic variables. Inferential statistics were used to assess differences in attitudinal, descriptive, and behavioral measures, which were cross-tabulated with demographic data. Data were analyzed using StatPac Software version 16 (Bloomington, Minnesota). Depending on data type, a 2-tailed independent samples t-test, a chi-square test, or a one-way analysis of variance was used to test for statistical significance $(p<0.05)$. Post hoc multiple comparisons used a Bonferroni adjustment to control the family-wise error rate. Two validated scales were used in the surveys: The Medication Adherence Report Scale (MARS-5) ${ }^{15}$ for patient adherence $(\mathrm{a}=0.88)$ and the modified Medical Research Council Dyspnea Scale (mMRC), ${ }^{16}$ a global measure of COPD symptom severity (see the online supplement).

\section{Results}

\section{Respondent Demographics}

The HCP survey was completed by $513 \mathrm{HCPs}$ ( $\mathrm{n}=209$ PUDs, $n=150$ PCPs, $n=154$ NPPs; average survey completion time, 12 minutes; response rate, $18 \%$ [additional information regarding response rate calculations provided in the online supplement]). Detailed HCP demographics are shown in Table 2. HCPs reported that COPD severity in their patients was evenly distributed among mild, moderate, severe, and very severe disease $(24 \%, 32 \%, 27 \%$, and $17 \%$, respectively). The patient survey was completed by 505 patients (average survey completion time, 16 minutes; response rate, $65 \%$ [additional information regarding response rate calculations provided in the online supplement]). Six surveys had a completion time significantly lower than the average and were excluded, resulting in 499 eligible surveys. Respondents were predominantly white, female, aged 55 to 74 years, and with some level of college education. Detailed patient characteristics are shown in Table 3.

\section{Inhaler Device Selection and Assessment}

When selecting maintenance treatment for patients with stable COPD, the majority of HCPs placed greater importance on medication class over device type (Figure 1a ). Furthermore, in newly diagnosed patients with either stable or post-exacerbation COPD, only about one-third of all HCPs considered the inhalation device to be highly important when prescribing medication (Figures $1 \mathrm{~b}$ and $1 \mathrm{c}$ ).

Approximately one-half of surveyed HCPs reported always or frequently considering the burden of learning a new device technique when prescribing multiple medications for COPD. In addition, when considering barriers to COPD management, the concern that medication was not getting into a patient's lungs because of poor device use was moderate among all HCPs (3.3 and 3.5 [5-point Likert-type scale] for mild to moderate and severe to very severe disease, respectively). Furthermore, when selecting a medication for newly diagnosed patients with COPD, only $45 \%$ of all HCPs assessed the ability to use the device in every patient. A statistically significant 


\section{Table 2. Health Care Professionals Demographics and Characteristics}

\section{PUDs, \% PCPs, \% NPPs, \% Total, \% $(n=209) \quad(n=150) \quad(n=154) \quad(N=513)$}

Years in Practice

\begin{tabular}{l|l|l|l|l}
\hline$\geq 20$ & 31 & 27 & 30 & 30 \\
\hline $10-19$ & 28 & 29 & 25 & 27 \\
\hline$<10$ & 41 & 44 & 45 & 43 \\
\hline$\geq \mathbf{5 0} \%$ of Patient & 43 & 18 & 51 & 38 \\
Base with COPD & & & &
\end{tabular}

\section{Region of Country}

\begin{tabular}{l|l|l|l|l}
\hline West & 17 & 18 & 12 & 16 \\
\hline South & 33 & 33 & 42 & 36 \\
\hline Midwest & 25 & 24 & 25 & 25 \\
\hline Northeast & 25 & 25 & 21 & 24 \\
\hline
\end{tabular}

\section{Location}

\begin{tabular}{l|l|l|l|l}
\hline Urban & 48 & 37 & 41 & 42 \\
\hline Suburban & 39 & 47 & 42 & 42 \\
\hline Rural & 13 & 16 & 17 & 15 \\
\hline
\end{tabular}

\section{Practice Structure}

\begin{tabular}{l|r|r|r|r}
\hline Single Specialty & 53 & 39 & 46 & 49 \\
\hline Multispecialty & 42 & 52 & 54 & 51 \\
\hline Solo Practitioner & 5 & 9 & -- & 0 \\
\hline $\begin{array}{l}\text { Academic Medical } \\
\text { Center (Yes) }\end{array}$ & 37 & 39 & 23 & 34 \\
\hline $\begin{array}{l}\text { Allocation of Duties } \\
\text { Patient Care }\end{array}$ & 75 & 80 & 70 & 75 \\
\hline Teaching & 11 & 10 & 16 & 12 \\
\hline Research & 5 & 3 & 4 & 4 \\
\hline Administration & 9 & 7 & 10 & 9 \\
\hline
\end{tabular}

$\mathrm{COPD}=$ chronic obstructive pulmonary disease; $\mathrm{NPP}=$ non-physician provider; $\mathrm{PCP}=$ primary care physician; $\mathrm{PUD}=$ pulmonologist

difference was found by HCP type $\left(\mathrm{x}^{2}(2)=320.7\right.$, $p=0.0001)$; post hoc tests showed PUDs (52\%) and NPPs (49\%) were significantly more likely to assess a patient's ability to use a device in every case compared to $\mathrm{PCPs}(32 \%)$ (PUDs versus PCP $p=0.001$; NPP versus PCP $p=0.012$ ) (Figure 2).

\section{Changing Medications or Devices}

The majority of HCPs (87\%) reported that they were much more likely to change or add medications than to switch to a different inhalation device with the same medication in patients with established COPD experiencing frequent exacerbations. Hospitalists (46\%) and PUDs (41\%) were reported to be the most likely to determine which medications and devices a patient is prescribed upon hospital discharge. The majority of PCPs and NPPs maintained the treatment plan provided upon discharge, whereas $50 \%$ of PUDs devised a new one (Figure 3).

\section{Educating Patients on Device Use}

Although fewer than half of all HCPs assessed the ability to use the device in every patient with newly diagnosed COPD as previously stated, the majority (88\%) reported educating their patients with COPD on proper inhaler device use. Individualized oneon-one training was reported by most HCPs overall (81\%) but less often by PCPs (67\%). Other common educational methods were the use of placebo devices (43\%), printed materials (43\%), and training on a patient's actual device (40\%). Using a 5-point Likerttype scale, HCPs were most likely to provide education on the correct use of a device (4.5), proper breathing technique (4.4), and the correct assembly of a device (4.2). Proper storage of a device (3.8), procedures for cleaning a device (3.7), and making minor repairs to a device (2.7) received less emphasis.

\section{Patient-Reported Medication Adherence}

More than three-quarters of patients reported taking their COPD medication all (55\%) or most $(26 \%)$ of the time. However, using MARS- 5 scores suggested that approximately only one-half (51\%) of patients had a high level of adherence to their COPD medication, 36\% had a medium level, and 13\% had a low level. Patients whose COPD was managed by a PUD were more likely to report high medication adherence than patients managed by a PCP ( $57 \%$ versus $47 \%)$. Patients with low adherence generally reported less understanding of their illness, less understanding of and satisfaction with their COPD management, and greater confusion and apprehension about their prescription medications. Although patients generally did not find it physically difficult to handle their medications or devices, those with low adherence were more likely to report trouble manipulating their medications or devices. Most patients (79\%) reported experiencing 1 or more physical issues that could impact their ability to correctly manipulate an inhaler device, and 58\% identified 2 or 3 impediments. Patients reported arthritis, difficulty with fine motor activities, and poor eyesight as the most common potential impediments to device use (Table 4).

\section{Patient Device Prioritization and Use}

Patients were much more likely to worry about the effectiveness of their COPD medication (49\% some, 


\section{Table 3. Patient Demographics and Characteristics}

\section{Demographic}

Percentage

\section{Age, years}

\begin{tabular}{l|l}
$<55$ & 18
\end{tabular}

$55-64+34$

\begin{tabular}{l|l}
$65-74$ & 35
\end{tabular}

\begin{tabular}{l|l}
$\geq 75$ & 13
\end{tabular}

\begin{tabular}{l|l}
\hline Gender (Female) & 57 \\
\hline
\end{tabular}

Educational Attainment

\begin{tabular}{l|r}
\hline College Graduate & 37 \\
\hline Some College & 42 \\
\hline Tech/Trade School & 6 \\
\hline High School Graduate or Lower & 15 \\
\hline Ethnicity & \\
\hline White & 93 \\
\hline African American & 3 \\
\hline Asian & 2 \\
\hline Latino & 6 \\
\hline
\end{tabular}

\section{Household Composition}

\begin{tabular}{l|c}
\hline Lives Alone & 28 \\
\hline Lives with Spouse/Partner & 48 \\
\hline Lives with Children & 17 \\
\hline Lives with Another Adult & 7 \\
\hline Region of Country & \\
\hline West & 23 \\
\hline South & 35 \\
\hline Midwest & 21 \\
\hline Northeast & 19 \\
\hline
\end{tabular}

\section{Location}

\begin{tabular}{l|l}
\hline Urban & 26 \\
\hline Suburban & 49 \\
\hline Rural & 25 \\
\hline
\end{tabular}

\section{Self-Reported Health Status}

\begin{tabular}{l|c}
\hline Poor & 10 \\
\hline Fair & 31 \\
\hline Average & 40 \\
\hline Very Good & 17 \\
\hline Excellent & 2 \\
\hline
\end{tabular}

\section{Level of Concern About Health}

\begin{tabular}{l|r} 
Very Concerning & 33 \\
\hline Somewhat Concerning & 53 \\
\hline Not Too Concerned & 13 \\
\hline Not Concerned & 1 \\
\hline
\end{tabular}

Rely on Caregiver for Assistance (No) 85

Participate in Regular Exercise (Yes) 48
Typical Amount of Exercise Time per Week

\begin{tabular}{|l|c|}
\hline$<1$ & 15 \\
\hline $1-2$ hours & 31 \\
\hline $2-4$ hours & 28 \\
\hline$\geq 4$ hours & 26 \\
\hline Experience with Tobacco Use & \\
\hline Current Smoker & 21 \\
\hline Former Smoker & 60 \\
\hline Never Smoked & 19 \\
\hline BMI & \\
\hline Normal (<24.9) & 19 \\
\hline Overweight (25-29.9) & 28 \\
\hline Obese ( $\geq 30)$ & 53 \\
\hline Duration of COPD & \\
\hline$<4$ years & 24 \\
\hline $4-9$ years & 37 \\
\hline$\geq 10$ years & 39 \\
\hline Dyspnea Scale (mMRC) & \\
\hline 0 & 21 \\
\hline 1 & 44 \\
\hline 2 & 22 \\
\hline 3 & 10 \\
\hline 4 & 2 \\
\hline Type of Medical Professional Managing COPD \\
\hline PCP & 48 \\
\hline PUD & 44 \\
\hline NPP & 2 \\
\hline None & 6 \\
\hline
\end{tabular}

\section{Frequency of Office Visits for COPD Management}

\begin{tabular}{l|l}
\hline 1 time/year & 26 \\
\hline $2-3$ times/year & 40 \\
\hline 4 times/year & 23 \\
\hline$>4$ times/year & 11 \\
\hline
\end{tabular}

$\mathrm{BMI}=$ body mass index; $\mathrm{COPD}=$ chronic obstructive pulmonary disease; mMRC=modified Medical Research Council Dyspnea Scale; NPP=nonphysician provider; $\mathrm{PCP}=$ primary care physician; $\mathrm{PUD}=$ pulmonologist

most, or all of the time) than the proper use of their device ( $19 \%$ some, most, or all of the time). Sixty-four percent of patients were never concerned about their device technique (Figure 4). Nearly three-quarters (72\%) of patients reported using an MDI (Figure 5), with one-third (33\%) reporting that they preferred an MDI and another $35 \%$ reporting no device preference. Patients with more severe symptoms ( $\mathrm{mMRC}$ score, $\geq 2$ ) were more likely to report using an SVN (49\%) than a DPI (39\%), MDI (38\%), or SMI (36\%).

When surveyed about the different inhaler devices used, the majority of patients reported that their 


\section{Figure 1. Health Care Providers' Impressions on Device Importance in COPD Treatment Decisions}

a. When you consider prescribing a maintenance medication for a newly diagnosed, stable COPD patient, which is more important in determining which medication to prescribe medication class or device type?

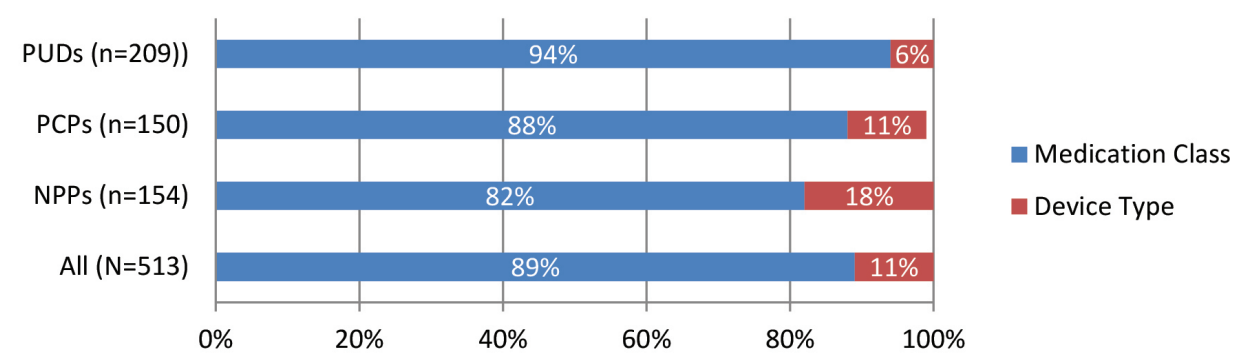

b. How important is the inhalation device in determining which medication you will prescribe to a newly diagnosed, stable COPD patient?

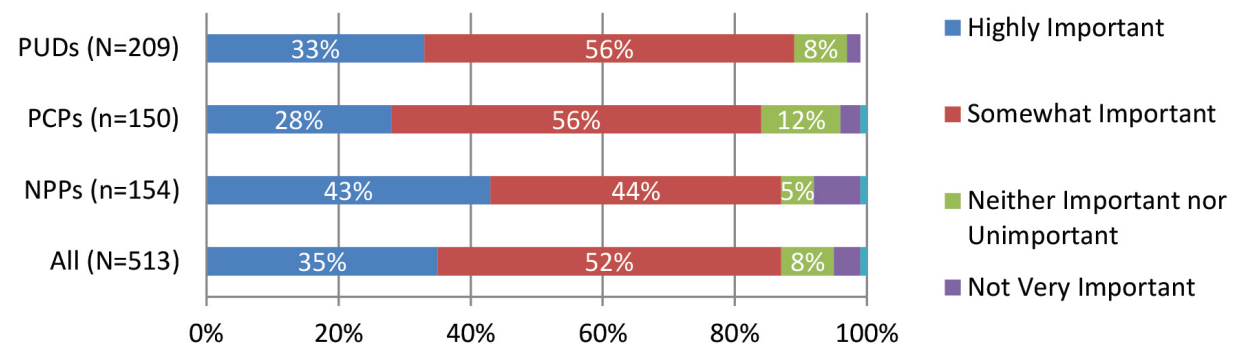

c. How important is the inhalation device in determining which medication you will prescribe to a newly diagnosed COPD patient who is post exacerbation?

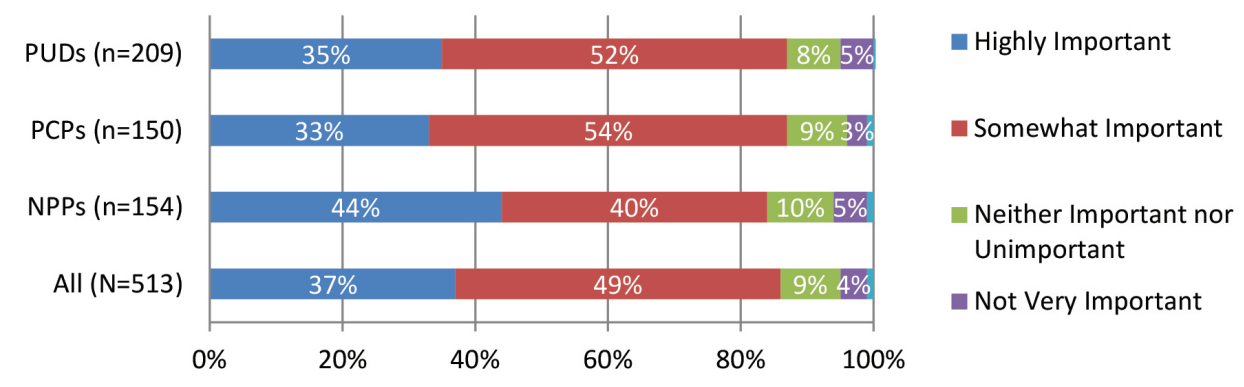

$\mathrm{COPD}=$ chronic obstructive pulmonary disease; $\mathrm{NPP}=$ non-physician provider; $\mathrm{PCP}=$ primary care physician; $\mathrm{PUD}=\mathrm{pulmonologist}$ 


\section{Figure 2. Health Care Providers' Frequency of Assessing Ability of Newly Diagnosed Patients to Use Device}

Do you assess a newly diagnosed patient's ability to use a particular type of delivery device when determining which medication to prescribe to manage their COPD?

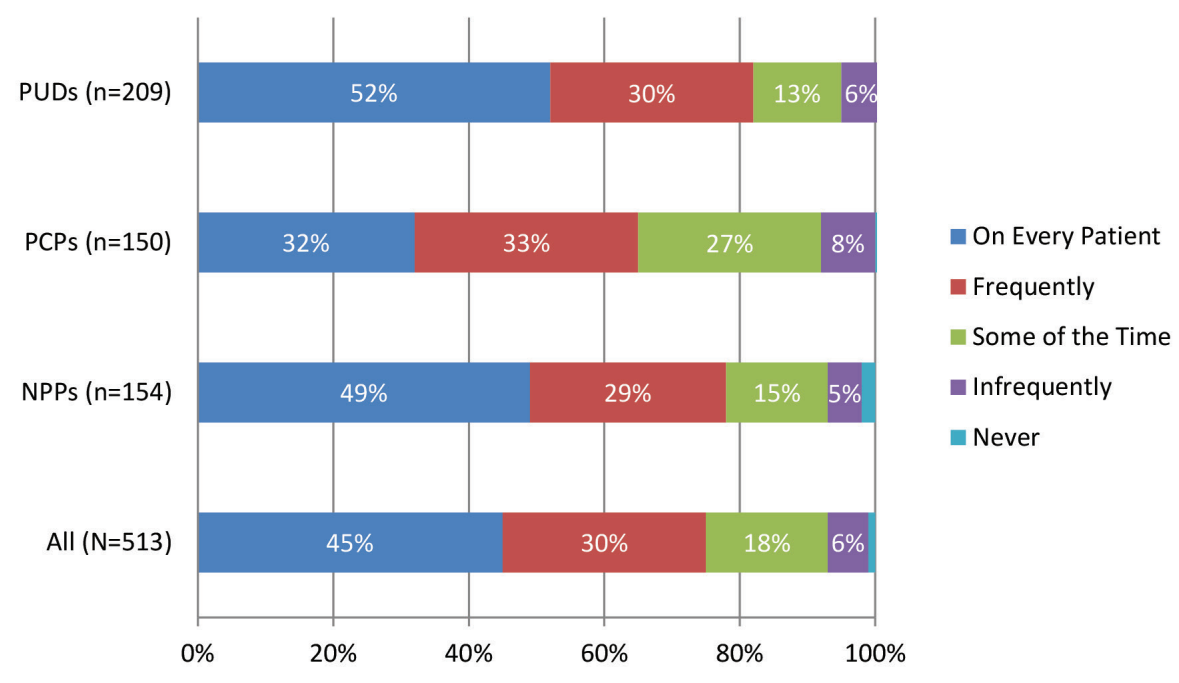

$\mathrm{COPD}=$ chronic obstructive pulmonary disease; $\mathrm{NPP}=$ non-physician provider; $\mathrm{PCP}=$ primary care physician; $\mathrm{PUD}=$ pulmonologist

\section{Figure 3. Health Care Providers' Approaches to Treatment After Hospital Discharge of Patients With COPD}

In following up on a patient after hospital discharge, do you typically maintain the treatment plan ordered at the hospital or devise a new treatment plan for the patient?

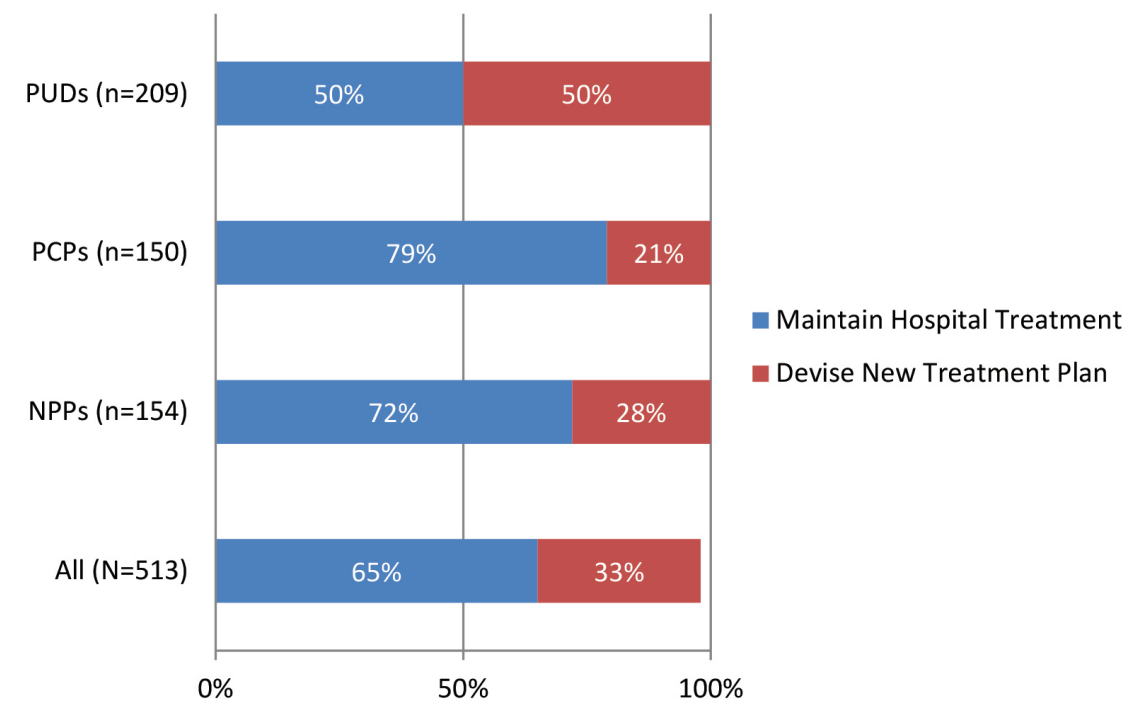


inhalation device, regardless of type, was very simple to use, assemble, and operate. However, a substantially greater percentage of patients who used SVNs (82\%) were "very confident about medication delivery" compared to patients who used DPIs (51\%), MDIs

\section{Table 4. Presence of Potential Impediments to Optimal Device Technique $(n=499)$}

\begin{tabular}{l|c} 
Impediment & Percentage \\
\hline Arthritis & 44 \\
\hline Difficulty with Fine Motor Activities & 36 \\
\hline Poor Eyesight & 33 \\
\hline Depression & 32 \\
\hline Poor Hearing & 29 \\
\hline Anxiety & 28 \\
\hline Memory Problems & 22 \\
\hline Tremor & 15 \\
\hline
\end{tabular}

(57\%), or SMIs (62\%). Most patients (61\%-69\%) believed that they used their device correctly all the time, with patients who used SVNs being most confident.

Only $52 \%$ of patients reported changes in treatment to access an easier-to-use device (Figure 6); this was more common in patients managed by PUDs compared to those managed by PCPs (63\% versus $42 \%$; $p=0.001$ ). Patients reported COPD symptoms and exacerbations as the most frequent reasons (57\%) for treatment changes. Patients who reported low adherence were more likely to undergo treatment changes due to "device issues" than patients with high adherence (13\% versus $3 \%$ ). Most patients reported undergoing some type of device training, although training was not uniform or complete (Table 5). Patients expressing higher satisfaction with their COPD management were more likely to have undergone training, and PUDs were more likely to have delivered extensive device training than PCPs.

\section{Figure 4. Frequency of Patients' Concerns About Medication Effectiveness and Device Technique}

Medication Effectiveness: Do you have concerns about how well your COPD medication is working?

Device Technique: Do you have concerns about how well your COPD medication is working based on any concerns that you have about your ability to properly use your inhaler device?

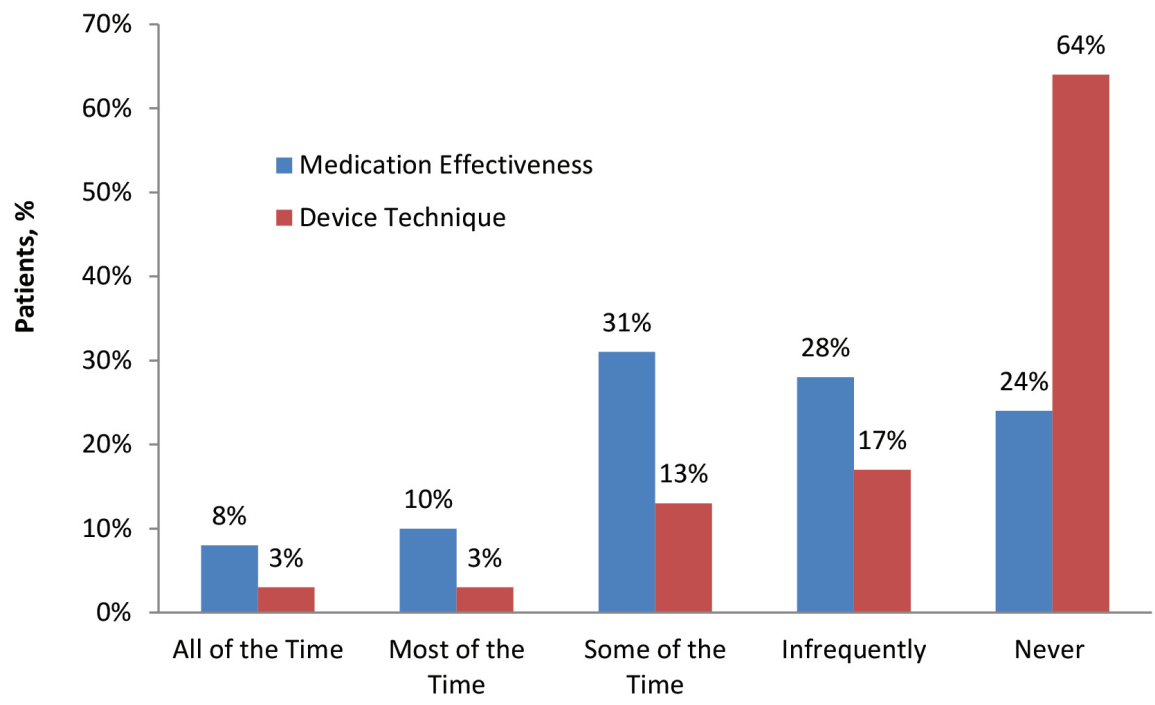

$\mathrm{COPD}=$ chronic obstructive pulmonary disease 


\title{
Figure 5. Patients' Use of and Preference for Inhalation Device Type
}

\author{
Do you currently use a DPI? \\ Do you currently use an MDI? \\ Do you currently use a hand held SVN? \\ Do you currently use an SMI? \\ If you could choose any type of inhaler device for delivery of your prescription medication, \\ which one would you prefer?
}

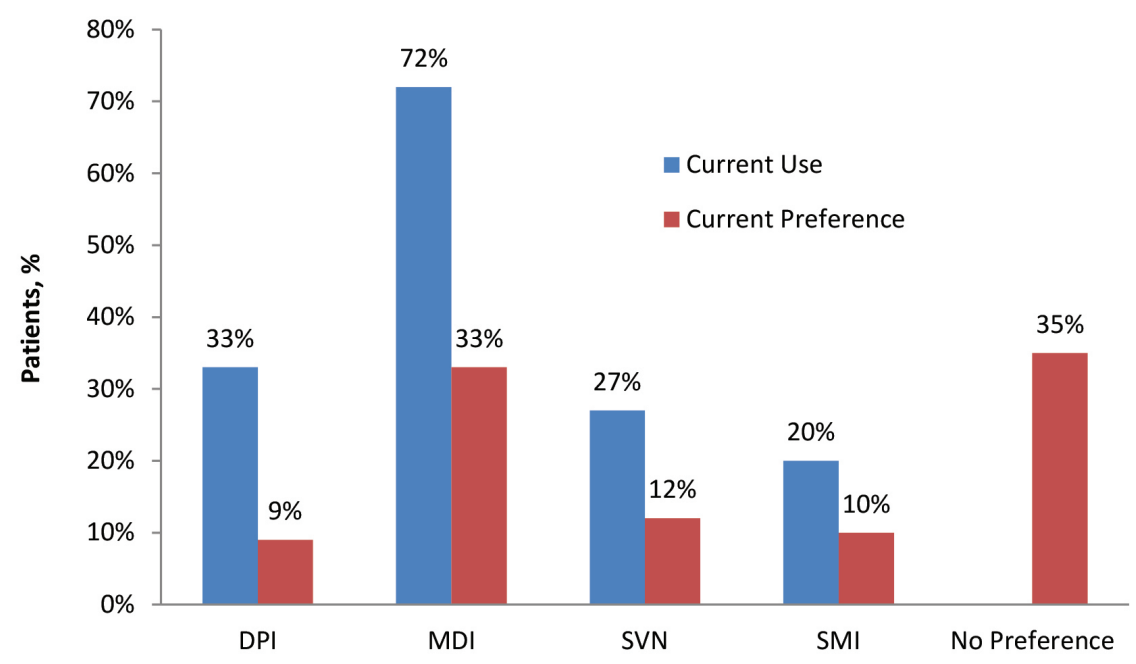

DPI=dry-powder inhaler; MDI=metered-dose inhaler; SMI=soft mist inhaler; SVN=small volume nebulizer

\section{Discussion}

Our findings unveil important HCP and patient perspectives about the role of inhalation devices in COPD treatment. Of note, both groups place more importance on the actual medication than its delivery device. Furthermore, concerns about proper device use are limited, with the ability to use inhalation devices not routinely assessed and inconsistent education given to ensure proper device use. Our HCP survey further demonstrates that device type is considered of limited importance when prescribing medication for newly diagnosed patients with stable or unstable COPD. Moreover, HCPs did not uniformly view poor device technique as a significant barrier to optimal COPD management, with fewer than half reporting that they assessed device technique in every newly diagnosed patient. This testing appeared to occur even less often among PCPs.

Consistent with our findings with HCPs, patients with COPD were relatively unconcerned with proper device technique, regardless of their COPD severity. Treatment changes were typically triggered by symptoms and exacerbations rather than poor device technique. Two factors, low-medication adherence and management by a PUD, were associated with a higher likelihood of changing treatment to access an easierto-use device. Despite limited concerns about device technique, potential barriers to optimal device use were relatively common among patients. Patients with the lowest medication adherence scores were more likely to cite physical difficulties when handling their medications or devices.

Interestingly, although most HCPs did not report consistently checking device technique in newly diagnosed patients, the majority reported providing 


\section{Figure 6. Percentage of Patients Who Had Their COPD Medication Changed to Access an Easier-to-Use Device}

Has your doctor ever made a change to the medications in your treatment plan specifically so that you would be able to use a different inhaler that might work better for you personally?

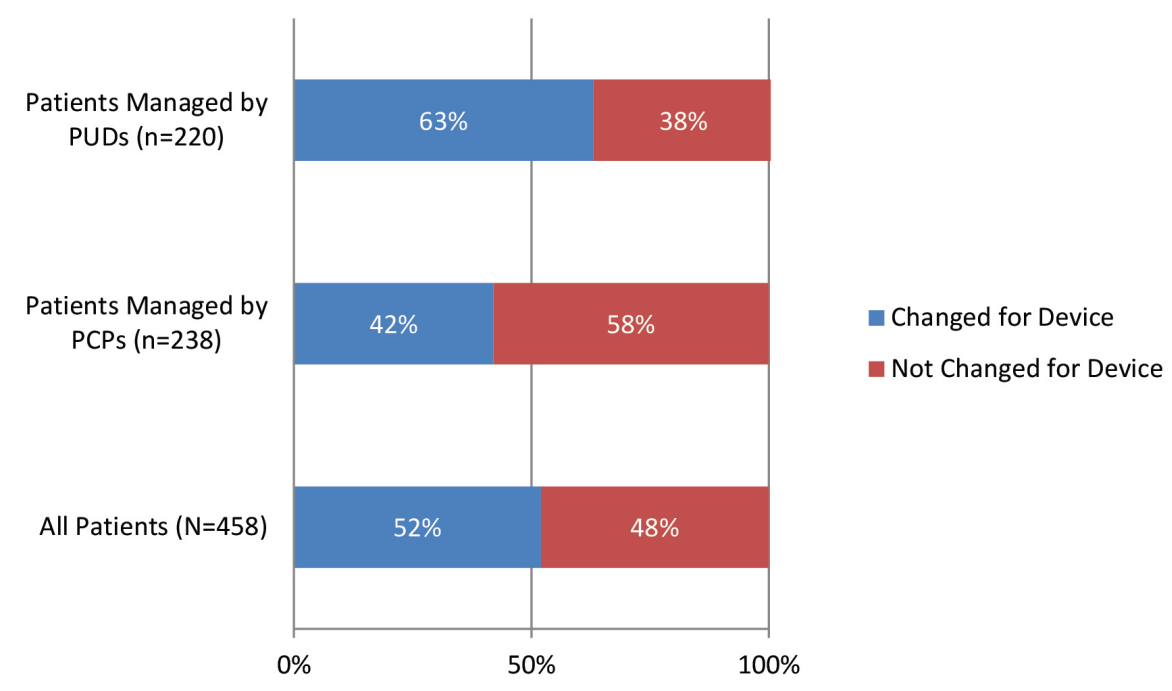

$\mathrm{COPD}=$ chronic obstructive pulmonary disease; $\mathrm{PCP}=$ primary care physician; $\mathrm{PUD}=$ pulmonologist

\section{Table 5. Percentage of Patients Reporting Device Training (By Physician Type and Satisfaction Level)}

\begin{tabular}{|c|c|c|c|c|c|c|}
\hline \multirow[t]{2}{*}{ Type of Training } & \multirow{2}{*}{$\begin{array}{c}\text { All } \\
\text { Patients }\end{array}$} & \multicolumn{2}{|c|}{ Physician Type } & \multicolumn{3}{|c|}{$\begin{array}{c}\text { Patient-Reported Level of Satisfaction } \\
\text { with COPD Management }\end{array}$} \\
\hline & & PCP & PUD & High & Medium & Low \\
\hline Instructions on How to Use Device & $76 \%$ & $75 \%$ & $84 \%$ & $83 \%$ & $77 \%$ & $61 \%$ \\
\hline Device Assembly & $66 \%$ & $66 \%$ & $71 \%$ & $71 \%$ & $69 \%$ & $47 \%$ \\
\hline Proper Breathing Technique & $79 \%$ & $79 \%$ & $86 \%$ & $86 \%$ & $83 \%$ & $59 \%$ \\
\hline Assessment of Ability to Use Device & $61 \%$ & $59 \%$ & $68 \%$ & $70 \%$ & $61 \%$ & $42 \%$ \\
\hline Use of Sample Device for Practice & $53 \%$ & $48 \%$ & $63 \%$ & $44 \%$ & $31 \%$ & $15 \%$ \\
\hline
\end{tabular}

$\mathrm{COPD}=$ chronic obstructive pulmonary disease; $\mathrm{PCP}=$ primary care physician; $\mathrm{PUD}=$ pulmonologist

individualized one-on-one training, although less often by PCPs. Furthermore, patients did not identify education as a significant impediment to proper device use, but most patients reported undergoing some type of device training, particularly if treated by PUDs. However, the educational experiences reported by patients were well short of universal, in relative contradistinction to the high educational efforts reported by HCPs. Greater efforts toward device education were associated with patients' higher satisfaction with their COPD management, suggesting the benefits of education extend beyond a patient's comfort level with device use. It is worth noting that resources are available to assist HCPs with device training from the COPD Foundation (https:// www.copdfoundation.org/Learn-More/For-PatientsCaregivers/Educational-Video-Series/Inhaler-TrainingVideos.aspx) and the American College of Chest Physicians (https://www.chestnet.org/Store/Products/ Standard-Products/eLearning/Respiratory-Devices-toManage-Obstructive-Lung-Disease).

Our findings support the work of other investigators 
who have urged for improved educational efforts to ensure the proper use of inhalation devices for people with chronic respiratory diseases, including COPD. ${ }^{6,7,17}$ Improper use of inhalers has been cited as a major factor in worsening outcomes for people with respiratory diseases, ${ }^{5}$ with up to $68 \%$ of patients with respiratory diseases (including COPD) not using their MDIs or DPIs appropriately. ${ }^{17}$ Inhaler misuse has been associated with a lack of device instruction by HCPs, and up to $67 \%$ of HCPs-including physicians, nurses, and respiratory care practitioners-reportedly cannot describe or perform basic steps of inhaler use. ${ }^{18}$ Poor inhalation device technique also has been linked to poorer clinical outcomes ${ }^{5,19}$ and disease control, as well as increased costs. ${ }^{20}$

Notably, our survey responses suggest that HCPs overestimate the extent and effectiveness of the device training they provide to their patients, which may limit the importance HCPs place on their own education around inhalation devices. It is of paramount importance that HCPs recognize the necessity of such professional education to be receptive to it. Education must also address HCP time constraints, which have been cited as a significant barrier to effective patient education on inhaler use. ${ }^{17}$ Ultimately, we see this type of professional education coordinating with patient-directed educational efforts to further promote the importance of proper device selection and use in COPD management.

Our study has several limitations, the most notable being the inherent selection bias in survey-based analyses. Additionally, the overall physician response rate was very low (18\%), which raises the possibility of nonresponse bias. Physician results could have been different had a greater proportion of invited physicians participated in the survey. Participants opted into the survey, so there is the possibility for self-selection of more motivated HCPs and patients. The sample size for NPPs was small and not evenly distributed among specialties, making subgroup analysis difficult. The study was performed in the United States; thus, we are unable to generalize our findings to other countries where access to care and inhalation device selection may be governed by other factors. Finally, a 2014 study by Tommelein et al demonstrated that MARS- 5 was not the most robust instrument for identifying nonadherence to inhalation medication in COPD. ${ }^{15}$ This was recognized at the study outset; however, it was chosen because it was easy for patients to self- administer and allowed for a general segmentation of the patient population by ranges of adherence scores.

\section{Conclusion}

In summary, our study uncovers several gaps in HCP and patient understanding of the role of inhalation devices in COPD management. It also highlights potential unmet needs and opportunities for future interventions to coordinate professional and patientdirected education to further promote proper device selection and use in COPD management.

\section{Acknowledgements}

Dr. Nicola A. Hanania takes responsibility for the content of the manuscript, including the data and analysis. All authors contributed to the conceptualization of the survey, the interpretation of the data, and the writing of all drafts of the manuscript. The authors also wish to acknowledge Barbara Martin, MD, Laura Sitler, BA, and Elizabeth Rappa, PharmD, of Health and Wellness Partners, Upper Saddle River, New Jersey, for editorial and writing support, and Mark Rudzinski of Rockpile Strategies, La Grange, Illinois, for data collection and analytical support.

\section{Declaration of Interest}

Sidney Braman has received honoraria for serving on advisory boards or has served as a consultant for AstraZeneca, Sunovion, and Genentech. Sandra G. Adams has been an investigator or received grants for research and continuing education from the National Institutes of Health, Veterans Affairs, The University of Texas System (Patient Safety Education Grant), the CHEST Foundation (GlaxoSmithKline Distinguished Scholar Award), AstraZeneca, Boehringer Ingelheim, Daiichi Sankyo, GlaxoSmithKline, Novartis, and Sunovion. Ruth Adewuya is an employee of the American College of Chest Physicians. Arzu Ari has received honoraria for serving on advisory boards or as a consultant for Bayer and Aerogen. She has received research support from ARC Medical. JoAnn Brooks has served on an advisory board for Eli Lilly and has participated in speakers' bureaus for Janssen and Sage. Nicola A. Hanania has received honoraria for serving on advisory boards or as a consultant for Boehringer Ingelheim, GlaxoSmithKline, Roche, AstraZeneca, Novartis, Sanof/Regeneron, and Teva. His institution has received research grant support 
from Sunovion, Mylan, Boehringer Ingelheim, Cheisi, AstraZeneca, Roche, and GlaxoSmithKline. Donald A. Mahler has served on advisory boards or speakers' bureaus for AstraZeneca, Boehringer Ingelheim, Sunovion, Theravance, and Grifols. He has received royalties from Hillcrest Media, CRC Press, and Mapi
Research Institute. Jill A. Ohar has received honoraria for serving on advisory boards for AstraZeneca, Novartis, Sunovion, and Mylan. Jay Peters has received research support from the Willard Foundation and the National Institute of Allergy and Infectious Disease. Shahin Sanjar is an employee of Sunovion. 


\section{References}

1. Global Initiative for Chronic Obstructive Lung Disease (GOLD). Global Strategy for the Diagnosis, Management, and Prevention of Chronic Lung Disease (2017 Report). GOLD website. http:// goldcopd.org/ Published 2017. Accessed December 2017.

2. Dolovich MB, Ahrens RC, Hess DR, et al. Device selection and outcomes of aerosol therapy: Evidence-based guidelines: American College of Chest Physicians/American College of Asthma, Allergy, and Immunology. Chest. 2005;127(1):335-371. doi: https://doi.org/10.1378/chest.127.1.335

3. Broeders ME, Sanchis J, Levy ML, Crompton GK, Dekhuijzen PNR. The ADMIT series: Issues in inhalation therapy-2. Improving technique and clinical effectiveness. Prim Care Respir J. 2009; 18(2):76-82. doi: https://doi.org/10.4104/pcrj.2009.00025

4. Hodder R, Price D. Patient preferences for inhaler devices in chronic obstructive pulmonary disease: experience with Respimat Soft Mist inhaler. Int J Chron Obstruct Pulmon Dis. 2009;4:381-390. doi: https://doi.org/10.2147/COPD.S3391

5. Yawn B, Colice GL, Hodder R. Practical aspects of inhaler use in the management of chronic obstructive pulmonary disease in the primary care setting. Int $J$ Chron Obstruct Pulmon Dis. 2012;7:495-502. doi: https://doi.org/10.2147/COPD.S32674

6. Geller DE. Comparing clinical features of the nebulizer, metered-dose inhaler, and dry powder inhaler. Respir Care. 2005;50(10):1313-1321.

7. Lavorini F, Mannini C, Chellini E. Challenges of inhaler use in the treatment of asthma and chronic obstructive pulmonary disease. EMJ Respir. 2015;3(2):98-105.

8. Melani AS, Bonavia M, Cilenti V, et al. Inhaler mishandling remains common in real life and is associated with reduced disease control. Respir Med. 2011;105(6):930-938. doi: https://doi.org/10.1016/j.rmed.2011.01.005

9. Loh CH, Peters SP, Lovings TM, Ohar JA. Suboptimal peak inspiratory flow rates are associated with chronic obstructive pulmonary disease and all-cause readmissions. Ann Am Thorac Soc. 2017;14(8):1305-1311.

doi: https://doi.org/10.1513/AnnalsATS.201611-903OC

10. Molimard M, Raherison C, Lignot S, Depont F, Abouelfath A, Moore N. Assessment of handling of inhaler devices in real life: an observational study in 3811 patients in primary care. $J$ Aerosol Med. 2003;16(3):249-254.

doi: https://doi.org/10.1089/089426803769017613

11. Sulaiman I, Cushen B, Greene G, et al. Objective assessment of adherence to inhalers by patients with chronic obstructive pulmonary disease. Am J Respir Crit Care Med. 2017;195(1):13331343. doi: https://doi.org/10.1164/rccm.201604-0733OC
12. Dudvarski Ilic A, Zugic V, Zvezdin B, et al. Influence of inhaler technique on asthma and COPD control: a multicenter experience. Int J Chron Obstruct Pulmon Dis. 2016;11:2509-2517. doi: https://doi.org/10.2147/COPD.S114576

13. Baverstock M, Woodhall N, Maarman V. Do healthcare professionals have sufficient knowledge of inhaler techniques in order to educate their patients effectively in their use? Thorax. 2010;65:A118. Abstract P94.

doi: https://doi.org/10.1136/thx.2010.150979.45

14. Braman S, Carlin B, Hanania N, et al. Results of a pulmonologist survey regarding knowledge and practices with inhalation devices for COPD. Respir Care. In press.

15. Tommelein E, Mehrys E, Van Tongelen I, Bruisselle G, Boussery K. Accuracy of the medication adherence report scale (MARS-5) as a quantitative measure of adherence to inhalation medication in patients with COPD. Ann Pharmacother. 2014;48(5):589-595. doi: https://doi.org/10.1177/1060028014522982

16. Mahler DA, Ward J, Waterman LA, McCusker C, ZuWallack R, Baird JC. Patient reported dyspnea in COPD reliability and association with stage of disease. Chest. 2009;136(6):1473-1479. doi: https://doi.org/10.1378/chest.09-0934

17. Ganguly A, Das AK, Roy A, et al. Study of properuse of inhalational devices by bronchial asthma or COPD patients attending a tertiary care hospital. J Clin Diagn Res. 2014;8(10):HC04-HC07. doi: https://doi.org/10.7860/JCDR/2014/9457.4976

18. Fink JB, Rubin BK. Problems with inhaler use: a call for improved clinician and patient education. Respir Care. 2005;50(10):13601374.

19. Molimard M, Raherison C, Lignot S, et al. Chronic obstructive pulmonary disease exacerbation and inhaler device handling: real-life assessment of 2935 patients. Eur Respir J. 2017;49(2). pii: 1601794. doi: https://doi.org/10.1183/13993003.01794-2016

20. Roggeri A, Micheletto C, Roggeri DP. Inhalation errors due to device switch in patients with chronic obstructive pulmonary disease and asthma: critical health and economic issues. Int $J$ Chron Obstruct Pulmon Dis. 2016;11:597-602. doi: https://doi.org/10.2147/COPD.S103335 